\title{
THE PROFILE OF FRACTURE IN PATIENTS UNDER 17 YEARS OF AGE AT RSUD DR SOETOMO IN THE PERIOD OF 2013-2014
}

\author{
Satria Nur Sya'ban $^{1 *}$, Widati Fatmaningrum² ${ }^{2}$, Sulis Bayusentono ${ }^{3}$ \\ ${ }^{1}$ Clinical Student of M.D Program, University of Airlangga - Dr. Soetomo General Hospital, \\ Surabaya \\ ${ }^{2}$ Staff of Public Health Departement, University of Airlangga, Surabaya \\ ${ }^{3}$ Department of Orthopaedic and Traumatology, Faculty of Medicine, Universitas Airlangga, \\ Dr Soetomo Hospital, Surabaya \\ *Correspondence: Satria Nur Sya'ban, Clinical Student of M.D Program Airlangga University- \\ Dr. Soetomo General Hospital, Surabaya \\ E-mail : satriansb@gmail.com
}

\begin{abstract}
ABSTRAK
Fraktur pada anak adalah masalah penting pada masayarakat dewasa ini. Sebuah sensus pemerintah menemukan bahwa kontributor tertinggi kasus fraktur di Indonesia adalah anak berusia dibawah 17 tahun. Peningkatan pesat dari penggunaan kendara bermotor, sebuah ciri dari perkembangan ekonomi di negara berkembang, menghasilkan peningkatan tajam dari saturasi jalan dan berakibat pada peningkatan cidera akibat kecelakaan lalu lintas. Fraktur pada anak-anak dapat menyebabkan kecacatan jangka panjang dan mengurangi kualitas hidup pada semua pihak yang terlibat, mengenai aspek mulai dari ekonomi sampe psikologis. Variabel yang berpengaruh pada fraktur anak harusdi identifikasi dan dipetakan untuk membuat dasar pembuatan tindakan pencegahan yang lebih baik sehingga dapat mengurangi masalah dari akarnya. Maka dari itu, tujuan dari riset ini adalah untuk membuat sebuah profil fraktur pada pasien berusia dibawah 17 tahun di RSUD Dr Seotomo. Riset ini adalah sebuah riset deskriptif yang dilakukan dengan menganalisa rekam medis di RSUD Dr Soetomo untuk variabel berikut ini: umur, jenis kelamin, jenis fraktur, penyebab fraktur, waktu fraktur, dan jarak antara MRS dan penanganan. Data lalu ditabulasi dan dibuat menjadi grafik untuk analisa lebih mudah. Riset ini menemukan bahwa fraktur pada anak paling sering terjadi pada umur 10-14 tahun $(41.8 \%)$, terjadi lebih sering pada laki-laki dibanding perempuan (69.5\%), di dominasi oleh fraktur tertutup dibanding fraktur terbuka (75.9\%), dan paling sering disebabkan oleh kecelakaan lalu lintas $(60.9 \%)$, dan maka dari itu, lokasi tempat fraktur paling sering terjadi adalah "Jalan" (63.1\%). Selain itu juga ditemukan bahwa fraktur paling sering terjadi pada pukul 12.01-18.00 (19.1\%) dan ditangani kurang dari 8 jam sejak MRS (79.4\%).

Kata kunci: fraktur, anak, dibawah 17 tahun, kecelakaan, profil
\end{abstract}

\begin{abstract}
Fractures in children are important problem nowadays. Governmental census lists people under 17 years old as the largest contributor to fracture cases in Indonesia. The rapid increase in motor vehicle use, a hallmark of economic growth in developing countries, led to sharp increase in road saturation and consequently, rise in traffic related injuries. Variables involved in pediatric fractures needs to be identified and mapped to provide basis for the creation of better preventive measures to reduce problem before it happens. Thus, the purpose of this research is to create a profile of fracture in patients under the age of 17 years' old at RSUD Dr Soetomo. The research is descriptive study which is performed by analyzing medical records in RSUD Dr Soetomo against the following: Age, Sex, Type of fracture, Cause of fracture, Time of fracture, Location of fracture, and Duration between admission and treatment.
\end{abstract}


Data is then tabulated and converted into a bar graph for easier analysis. The research found that fractures in children most commonly occur at the 10-14 years' age group (41.8\%), happens more frequently in boys than in girls $(69.5 \%)$, is dominated by closed fractures over open fractures $(75.9 \%)$, and is most often caused by traffic accidents $(60.9 \%)$. Consequently, the location in which fractures are most prevalent is the "street" $(63.1 \%)$. It is also found that the highest incidence of fractures cases happens within the 12.01-18.00 time-span (19.1\%) and is treated within the first 8 hours of admission to the hospital $(79.4 \%)$.

Keywords: fractures, children, under 17 years' old, accidents, profile

\section{PENDAHULUAN}

Sebuah riset oleh Riyadina et al (2009) menyebutkan bahwa kecelakaan lalu lintas merupakan penyebab utama cedera di negara berkembang. Riset kesehatan dasar Indonesia (2013) juga menunjukkan bahwa patah tulang sebagai penyebab terbanyak keempat dari cedera di Indonesia. Jawa Timur secara khusus memiliki jumlah kasus patah tulang yang melebihi rata-rata kasus nasional dengan nilai $6.0 \%$ dibanding $5.8 \%$ (Riskesdas, 2013)

Fraktur dapat menyebabkan kecacatan jangka panjang (Budd, 2012) dan dapat menyebabkan turunnya Quality of Life dan meningkatkan kebutuhan biaya hidup sehari-hari bagi penderita (Bonafede et al, 2013). Bonafede et al (2013) menunjukkan bahwa fraktur tulang pipa dapat meningkatkan biaya hidup seorang pasien menjadi dua hingga tiga kali lipat dari batas normal. Hal ini dapat berdampak negatif terhadap produktivitas ekonomi dan sosial seseorang.
Banyak faktor yang mempengaruhi insiden patah tulang. Salah satunya adalah umur: total insiden patah tulang pada anak dibawah 17 tahun (11.4\%) paling tinggi saat dibandingkan dengan kelompok umur lainnya (Riskesdas, 2013). Selain umur, data Riskesdas (2013) juga menunjukkan bahwa jenis kelamin dan tempat kejadian memiliki hubungan dengan insiden fraktur tulang: laki-laki (6.6\%) lebih rentan terhadap fraktur tulang dibanding wanita (4.6\%) dan penduduk pedesaan $(6.0 \%)$ lebih sering mengalami fraktur daripada penduduk daerah perkotaan $(5.7 \%)$.

Rumah Sakit Universitas Robert Wood Johnson (2012) mengatakan bahwa waktu yang paling rentan untuk cedera adalah waktu sore menjelang malam sedangkan Moran et al (2005) menekankan hubungan positif antara rentang waktu antara kejadian fraktur dan tindakan dengan tingkat mortalitas pasien.

Fakta bahwa Anak-anak adalah golongan yang rentan terhadap terjadinya patah tulang dikonfirmasi oleh Staheli 
(2008), dengan pernyataan bahwa $15 \%$ dari kasus trauma pada anak-anak adalah trauma muskuloskeletal dan resiko ini umumnya berhubungan dengan tingginya tingkat aktivitas anak-anak dalam kegiatan mereka sehari-hari. (Staheli, 2008)

Walaupun sudah ada data lengkap tentang demografi cidera pada anak di Indonesia, namun untuk fraktur tulang akibat kecelakaan di RSUD Dr Soetomo sendiri belum ada data yang cukup jelas.

Data profil fraktur pada anak sangat penting, karena dapat digunakan sebagai informasi edukasi dan pembuatan sistem pencegahan yang lebih efisien di masa mendatang. Oleh karena itu, penelitian ini bertujuan untuk memberikan gambaran profil fraktur tulang pada pasien berusia dibawah 17 tahun di RSUD Dr. Soetomo dalam periode 2013-2014.

\section{METODE}

\section{Rancangan Penelitian}

Penelitian ini menggunakan desain penelitian deskriptif untuk mengetahui profil fraktur tulang pada pasien berusia dibawah 17 tahun di RSUD Dr. Soetomo Surabaya.

\section{Populasi dan Sampel}

\section{- Populasi}

Populasi pada penelitian ini adalah pasien anak dibawah umur 17 tahun dengan kondisi fraktur tulang di RSUD Dr. Soetomo dalam periode 1 Januari 2013-31 Desember 2014.

\section{- Kriteria Sampel}

\section{Inklusi}

a. Pasien tercatat pada Rekam Medis RSUD Dr Soetomo

b. Data pasien memenuhi minimal 4 dari 7 Variabel yang dicari

\section{Eksklusi}

a. Pasien dengan Multiple Fracture

b. Pasien dengan fraktur patologis akibat tumor, rickettsia, osteogenesis imperfekta, dan kelainan kongenital tulang

\section{- Sampel}

Besar sampel yang digunakan dalam penelitian ini merupakan total sampling seluruh penderita fraktur tulang yang diperiksa di RSUD Dr. Soetomo selama 2 tahun (periode Januari 2013 - Desember 2014).

\section{Variabel Penelitian}

Variabel yang digunakan pada penelitian ini adalah umur, jenis kelamin, jenis patah tulang, penyebab, lokasi kejadian, waktu kejadian, dan penanganan awal. 


\section{Instrumen Penelitian}

Instrumen penelitian yang digunakan adalah dokumen rekam medis pasien fraktur tulang dari bagian Rekam Medis RSUD Dr. Soetomo selama 2 (dua) tahun terakhir (Mulai 1 Januari 2013 - 31 Desember 2014)

\section{Lokasi dan Waktu Penelitian}

\section{- Lokasi Penelitian}

Penelitian ini dilakukan di Bagian

Rekam Medis RSUD Dr Soetomo.

\section{- Waktu Penelitian}

Waktu pelaksanaan penelitian ini pada bulan Agustus-Desember 2015.

\section{Prosedur Penelitian dan Pengumpulan \\ Data}

Penelitian ini menggunakan data sekunder yang diperoleh dari Rekam medik penderita di Bagian Rekam Medik RSUD Dr Soetomo.

\section{Analisis Data}

Variabel yang dikaji pada penelitian ini adalah umur, jenis kelamin, jenis patah tulang, penyebab patah tulang, lokasi kejadian, waktu kejadian, dan waktu hingga penanganan awal. Analisis data dilakukan secara deskriptif.

\section{- Prosedur Analisis Data}

Mahasiswa akan datang ke Departemen Ortopaedi dan Traumatologi
RSUD Dr Soetomo Surabaya dan mencari data sekunder berupa database pasien fraktur tulang. Setelah mendapatkan data yang dicari, data tersebut lalu di proses melalui kriteria inklusi dan eksklusi dan proses tabulasi sehingga menghasilkan Profil fraktur tulang pada pasien berusia dibawah 17 tahun di RSUD Dr Soetomo dalam periode Januari 2013 - Desember 2014.

\section{HASIL DAN PEMBAHASAN}

Penelitian dilakukan dengan menelaah rekam medis yang didapatkan dari Bagian Rekam Medis RSUD Dr Soetomo Surabaya untuk variabel umur, jenis kelamin, jenis fraktur, penyebab fraktur, waktu kejadian, lokasi kejadian, dan waktu hingga penanganan awal. Sampel yang seharusnya digunakan berjumlah 296 berdasarkan data indeks rekam medis yang didapatkan dari Bagian Rekam Medis RSUD Dr Soetomo, dengan 214 sampel yang tersedia dalam periode waktu pengambilan data. Diantara sampel yang tersedia, 141 data (65.9\%) termasuk valid berdasarkan kriteria inklusi dan eksklusi yang telah ditentukan sebelumnya. 


\section{Umur}

Pembagian umur yang digunakan adalah "five-year age groups", yang merupakan standar pembagian umur untuk tujuan statistika dan demografi.

Tabel 1. Distribusi frekuensi responden berdasarkan umur di RSUD Dr Soetomo tahun $2013-2014$

\begin{tabular}{ccc}
\hline Umur & $\begin{array}{c}\text { Jumlah } \\
(\mathbf{n})\end{array}$ & $\begin{array}{c}\text { Persentase } \\
(\mathbf{\%})\end{array}$ \\
\hline$<0$ tahun & 0 & 0 \\
01 - 04 tahun & 20 & 14.2 \\
05 - 09 tahun & 19 & 13.5 \\
10 - 14 tahun & 59 & 41.8 \\
$>$ 15 tahun & 43 & 30.5 \\
\hline Total & $\mathbf{1 4 1}$ & $\mathbf{1 0 0}$ \\
\hline
\end{tabular}

Sesuai dengan data yang disajikan pada tabel 1, kasus fraktur yang dirawat di RSUD Dr Soetomo paling sering terjadi pada pasien dalam kelompok umur $10-14$ tahun dengan jumlah 59 kasus $(41.8 \%)$. Hal ini sesuai dengan Vopat et al. (2014) serta Hart et al (2006) yang mengatakan bahwa fraktur tertentu, antara lain fraktur eminensia tibia dan lengan bawah memang terjadi paling sering pada kelompok umur 10-14 tahun.

Penemuan jumlah yang cukup tinggi pada kelompok umur > 15 tahun, yakni 43 kasus (30.5\%), didukung oleh Peden (2004), yang mengatakan bahwa jumlah fraktur karena kecelakaan lalu lintas paling tinggi pada kelompok umur 15-19 tahun, dan data dari Korlantas Polri (2013) yang juga menunjukkan bahwa jumlah cedera akibat kecelakaan lalu lintas paling tinggi pada umur 15-19 tahun.

Blows et al (2005) mengatakan bahwa perilaku mengendarai kendaraan bermotor tanpa surat izin mengemudi memiliki korelasi dengan resiko kecelakaan yang lebih tinggi. Kedua kelompok umur di atas adalah kelompok umur yang belum memenuhi syarat untuk memiliki Surat Izin Mengemudi (SIM) dan karena itu diperkirakan bahwa jumlah cedera yang tinggi pada kelompok umur ini disebabkan oleh faktor perilaku, yaitu perilaku mengendarai kendaraan bermotor tanpa surat izin mengemudi.

Jumlah 20 kasus (14.2\%) pada kelompok umur 0-4 tahun dan 19 kasus (13.5\%) pada kelompok umur 5-9 tahun cukup rendah karena pada umur-umur tersebut anak-anak masih sangat dijaga oleh orang tua dan belum mulai mengendarai kendaraan bermotor.

\section{Jenis kelamin}

Pada tabel 2 dapat dilihat bahwa anak laki-laki lebih sering terkena fraktur dibandingkan anak perempuan dengan 
jumlah 98 kasus (69.5\%) dibanding 43 kasus $(30.5 \%)$. Data yang ditemukan oleh Valerio et al., (2010) menunjukkan hal yang sama, dimana anak laki-laki memiliki resiko dan jumlah kejadian fraktur yang lebih tinggi dikarenakan tingginya mobilitas dan partisipasi mereka dalam kegiatan berolahraga.

$$
\text { Selain itu, Peden }
$$
mengatakan bahwa anak laki-laki memiliki resiko lebih tinggi untuk terlibat dalam kecelakaan lalu lintas. Hal ini diperkirakan juga menyebabkan jumlah kejadian fraktur yang lebih tinggi pada anak laki-laki.

Tabel 2. Distribusi frekuensi responden berdasarkan jenis kelamin di RSUD Dr Soetomo tahun 2013-2014

\begin{tabular}{ccc}
\hline $\begin{array}{c}\text { Jenis } \\
\text { Kelamin }\end{array}$ & $\begin{array}{c}\text { Jumlah } \\
(\mathbf{n})\end{array}$ & $\begin{array}{c}\text { Persentase } \\
(\boldsymbol{\%})\end{array}$ \\
\hline Laki-Laki & 98 & 69.5 \\
Perempuan & 43 & 30.5 \\
\hline Total & $\mathbf{1 4 1}$ & $\mathbf{1 0 0}$ \\
\hline
\end{tabular}

\section{Jenis fraktur}

Pada tabel 3 dapat dilihat bahwa Closed fracture adalah jenis yang lebih sering terjadi, dengan jumlah 107 kasus (75.9\%) dibandingkan Open Fracture dengan jumlah 34 kasus (24.1\%). Sebuah riset tentang epidemiologi fraktur di dalam sebuah rumah sakit di India oleh Sharma,
Ali dan Ubbot (2006) menunjukkan pola yang hampir sama, dimana jumlah kejadian Closed Fracture (73.8\%) jauh lebih tinggi dibandingkan Open Fracture (26.2\%). Penelitian lain di sebuah rumah sakit di Nigeria oleh Igho et al (2015) juga menunjukan jumlah kejadian Closed Fracture yang lebih tinggi dari pada Open Fracture, membuktikan bahwa hal ini tidak region-specific.

Penyebab jumlah yang sangat berbeda ini diperkirakan adalah karena pada penelitian ini Closed Fracture mencakup banyak jenis fraktur, antara lain: fraktur Avulsi, fraktur Greenstick, fraktur Hairline, fraktur Comminuted, dan faktur Kompresi. Ragam Closed Fracture yang luas berarti tingkat dan jenis cedera yang menyebabkan jenis fraktur ini juga beragam, mulai dari cedera ringan hingga berat; berlawanan dengan Open Fracture yang biasanya disebabkan oleh trauma berenergi tinggi yang sering menyebabkan disabilitas lain juga pada pasien yang bersangkutan (Cannada, 2011).

Tabel 3. Distribusi frekuensi responden berdasarkan jenis fraktur di RSUD Dr Soetomo tahun 2013 - 2014 


\section{Penyebab fraktur}

Pada tabel 4 dapat dilihat bahwa, dengan jumlah 86 kasus (60.9\%), kecelakaan lalu lintas adalah penyebab terbanyak fraktur yang dirawat di RSUD Dr Soetomo. Hasil ini didukung oleh data dari World Report on Traffic Injury Prevention yang mengatakan bahwa jumlah anak yang terluka atau menderita kecacatan akibat kecelakaan lalu lintas mencapai 10 juta jiwa setiap tahunnya (Peden, 2004). Resiko mengalami fraktur akibat kecelakaan lalu lintas meningkat pada pengendara yang tidak memiliki SIM dan tidak memakai helm (Blows et al., 2005), kedua hal yang sangat lazim ditemukan dalam populasi dengan sosioekonomi menengah kebawah di Indonesia. Di Surabaya, rasio antara volume dan kapasitas maksimal jalan sudah mencapai 0.9 , yang berarti jalan sudah hampir dipenuhi kapasitasnya (Tahir, 2005). Kepadatan yang sangat tinggi ini diduga menjadi juga menjadi faktor pendukung tingginya kejadian fraktur karena kecelakaan lalu lintas.

Jatuh dan terpeleset adalah dua penyebab fraktur lainnya dengan jumlah 36 kasus $(25.5 \%)$ dan 3 kasus $(2.1 \%)$ secara berurutan. Jatuh yang tidak disengaja adalah salah satu cedera yang paling sering

\begin{tabular}{ccc}
\hline $\begin{array}{c}\text { Jenis } \\
\text { Fraktur }\end{array}$ & $\begin{array}{c}\text { Jumlah } \\
(\mathbf{n})\end{array}$ & $\begin{array}{c}\text { Persentase } \\
(\mathbf{\%})\end{array}$ \\
\hline Open & 34 & 24.1 \\
$\begin{array}{c}\text { Fracture } \\
\text { Closed }\end{array}$ & 107 & 75.9 \\
Fracture & & $\mathbf{1 0 0}$ \\
\hline Total & $\mathbf{1 4 1}$ & \\
\hline
\end{tabular}

menyebabkan cedera non-fatal pada anak dan dari seluruh populasi dunia, anak dibawah umur 10 tahun dan orang tua diatas 65 tahun adalah kelompok umur yang paling beresiko (Gill dan Kelly, 2015; Peden, 2004). Selain itu, data juga menunjukkan bahwa banyak kasus fraktur pada anak usia sekolah terjadi akibat jatuh. Hal ini diperkirakan terjadi karena lingkungan yang kurang aman, strata sosioekonomik rendah, kemampuan motorik yang belum berkembang sempurna pada anak-anak (World Health Organization, 2012) dan berbagai faktor lain yang merupakan faktor pendukung terjadinya insiden jatuh dan terpeleset pada anak-anak.

Tabel 4. Distribusi frekuensi responden berdasarkan penyebab fraktur di RSUD Dr Soetomo tahun 2013 - 2014

\begin{tabular}{ccc}
\hline Penyebab & $\begin{array}{c}\text { Jumlah } \\
(\mathbf{n})\end{array}$ & $\begin{array}{c}\text { Persentase } \\
(\boldsymbol{\%})\end{array}$ \\
\hline Kecelakaan & 86 & 60.9 \\
lalu lintas & 36 & 25.5 \\
Jatuh & 3 & 2.1 \\
Terpeleset & 7 & 5.0 \\
Lainnya & 9 & 6.4 \\
No data & $\mathbf{1 4 1}$ & $\mathbf{1 0 0}$ \\
\hline Total &
\end{tabular}




\section{Waktu kejadian}

Pada tabel 5 dapat dilihat bahwa waktu kejadian yang paling sering terjadi adalah pukul 12.01-18.00 dengan jumlah 27 kasus (19.1\%), diikuti dengan kejadian pada pukul 06.01-12.00 dengan jumlah 12 kasus $(8.5 \%)$. Hal ini sesuai dengan riset oleh Wicaksono et al., (2014) menunjukkan bahwa kejadian kecelakaan di ruas jalan Ungaran - Bawen paling tinggi pada kelompok waktu 12.01 - 18.00. Jalan di Surabaya, seperti halnya jalan Ungaran Bawen memiliki dua peak hours kepadatan, yaitu pukul 07.00 dan pukul 16.00 (Rozari dan Wibowo, 2015). Kepadatan ini diperkirakan adalah penyebab tingginya kejadian fraktur pada dua kelompok waktu tersebut. Waktu kejadian terbanyak berikutnya adalah pukul 18.01-00.00 dengan jumlah 11 kasus (7.8\%) dan terakhir adalah kejadian pada pukul 00.01-06.00 dengan jumlah 7 kasus (5.0\%)

Pada penelitian ini, juga ditemukan bahwa 84 rekam medis (59.6\%) tidak memiliki data mengenai waktu kejadian kecelakaan, yang seharusnya tertulis sebagai "Jam Kejadian" dari penyakit.
Faktor yang mendukung tidak lengkapnya rekam medis pada sebuah fasilitas layanan kesehatan adalah aspek sumber daya manusia yaitu ketidakdisiplinan dokter dan perawat dalam mengisi rekam medis, dikarenakan prioritas mereka untuk memberikan pelayanan dan kurangnya waktu kosong untuk mengisi rekam medis (Pamungkas et al, 2015)

Tabel 5. Distribusi frekuensi responden berdasarkan waktu kejadian di RSUD Dr Soetomo tahun 2013 - 2014

\begin{tabular}{ccc}
\hline $\begin{array}{c}\text { Waktu } \\
\text { Kejadian }\end{array}$ & $\begin{array}{c}\text { Jumlah } \\
(\mathbf{n})\end{array}$ & $\begin{array}{c}\text { Persentase } \\
(\boldsymbol{\%})\end{array}$ \\
\hline $00.01-06.00$ & 7 & 5.0 \\
$06.01-12.00$ & 12 & 8.5 \\
$12.01-18.00$ & 27 & 19.1 \\
$18.01-00.00$ & 11 & 7.8 \\
$\begin{array}{c}\text { Data tidak } \\
\text { tersedia }\end{array}$ & 84 & 59.6 \\
\hline Total & $\mathbf{1 4 1}$ & $\mathbf{1 0 0}$ \\
\hline
\end{tabular}

\section{Lokasi kejadian}

Pada tabel 6 dapat dilihat bahwa Jalan adalah lokasi kejadian terbanyak untuk fraktur yang dirawat di RSUD Dr Soetomo dengan jumlah 89 kasus (63.1\%). Hal ini sesuai dengan data yang ditemukan pada penelitian ini, dimana kecelakaan lalu lintas menjadi penyebab kejadian fraktur terbanyak di RSUD Dr Soetomo. Menurut Nantulya (2002), kejadian fraktur pada 


\begin{tabular}{ccc}
\hline Lokasi Kejadian & $\begin{array}{c}\text { Jumlah } \\
(\mathbf{n})\end{array}$ & $\begin{array}{c}\text { Persenta } \\
\text { se (\%) }\end{array}$ \\
\hline Jalan & 89 & 63.1 \\
Lapangan /Taman & 25 & 17.7 \\
Rumah & 15 & 10.6 \\
Data tidak & 8 & 5.7 \\
tersedia & 4 & 2.8 \\
Lainnya & 4 & $\mathbf{1 0 0}$ \\
\hline Total & $\mathbf{1 4 1}$ &
\end{tabular}

anak akibat kecelakaan lalu lintas sangat tinggi di regio Asia Pasifik. Hal ini terjadi karena pesatnya perkembangan jumlah kendaraan bermotor yang tidak diimbangi dengan regulasi lalu lintas yang baik, menyebabkan jalan menjadi sebuah lokasi resiko tinggi untuk kejadian fraktur.

Lapangan dan Rumah menjadi lokasi kejadian terbanyak kedua dan ketiga dengan jumlah $25(17.7 \%)$ dan $15(10.6 \%)$ kasus. Sesuai dengan data yang ditemukan pada penelitian ini, jatuh dan terpeleset adalah dua penyebab fraktur pada anak yang cukup umum dan Sleet et al., (2012) menemukan bahwa anak-anak sering jatuh dari berbagai lokasi seperti jendela, gedung, taman bermain, dan kasur (yang berada di Lapangan dan Rumah). Selain itu, jatuh karena kegiatan berolahraga juga menjadi kontributor pada tingginya kejadian fraktur di Lapangan, terutama pada anak-anak yang aktif dalam kegiatan olah raga. (Sleet et al., 2012)
Tabel 6. Distribusi frekuensi responden berdasarkan lokasi kejadian di RSUD Dr Soetomo tahun 2013 - 2014

Delapan $(5.7 \%)$ dari rekam medis yang digunakan, tidak memiliki catatan akan lokasi kejadian fraktur pasien yang bersangkutan, sehingga dikategorikan sebagai "Data tidak tersedia"

\section{Waktu hingga penanganan awal}

Seperti dapat dilihat pada tabel 7, mayoritas fraktur di RSUD Dr Soetomo telah mendapatkan perawatan dalam 8 jam pertama sejak MRS (112 kasus; 79.4\%). Angka ini sesuai dengan berbagai pedoman penanganan fraktur, yang mengatakan bahwa golden period penanganan fraktur adalah 6-8 jam (Salter, 1999). Penanganan cepat dari fraktur, terutama fraktur terbuka dapat mengurangi resiko infeksi dan menghindari komplikasi lainnya seperti sindroma kompartemen, malunion, maupun non-union dari tulang tersebut (Hackney dan Dodds, 2011).

Adanya kasus yang ditangani $>8$ Jam sejak MRS, sejumlah 18 kasus (12.8\%), diperkirakan terjadi karena volume pasien yang tinggi pada saat itu dan sifat dari cedera yang tidak darurat atau 
bersifat kosmetik, sehingga penanganan baru diberikan $>8$ jam sejak MRS pasien ke rumah sakit. Kemungkinan lain adalah apabila pencatatan rekam medis tidak sempurna; pada penelitian ini jarak waktu hingga penanganan awal didapatkan dari catatan pertama adanya tindakan pada pasien, jadi apabila ada tindakan stabilisasi yang tidak tercatat, akan muncul sebagai fraktur yang ditangani > 8 jam sejak MRS.

Pada tabel juga dapat dilihat bahwa, 11 kasus (7.8\%) tidak memiliki catatan waktu MRS ataupun penanganan, sehingga sebuah jarak antara MRS dan penanganan tidak bisa secara tepat disimpulkan (Data tidak tersedia).

Tabel 7. Distribusi frekuensi responden berdasarkan waktu hingga penanganan awal di RSUD Dr Soetomo tahun 2013 -

\begin{tabular}{ccc}
\hline $\begin{array}{c}\text { Waktu hingga } \\
\text { penanganan } \\
\text { awal }\end{array}$ & $\begin{array}{c}\text { Jumlah } \\
(\mathbf{n})\end{array}$ & $\begin{array}{c}\text { Persenta } \\
\text { se }(\%)\end{array}$ \\
\hline < 8 Jam & 112 & 79.4 \\
> 8 Jam & 18 & 12.8 \\
$\begin{array}{c}\text { Data tidak } \\
\text { tersedia }\end{array}$ & 11 & 7.8 \\
\hline Total & $\mathbf{1 4 1}$ & $\mathbf{1 0 0}$ \\
\hline
\end{tabular}

\section{KESIMPULAN DAN SARAN}

\section{Kesimpulan}

1. Fraktur paling sering terjadi pada kelompok umur 10-14 tahun

2. Jenis kelamin yang paling sering terkena fraktur adalah Laki-laki

3. Jenis fraktur yang paling sering terjadi adalah Closed Fracture

4. Penyebab fraktur yang paling banyak adalah kecelakaan lalu lintas

5. Fraktur paling sering terjadi pada rentang waktu pukul 12.01-18.00

6. Lokasi fraktur yang paling sering adalah di jalan

7. Mayoritas fraktur sudah ditangani $<8$ Jam setelah masuk ke rumah sakit

\section{Saran}

Riset lebih lanjut dengan periode waktu yang lebih panjang butuh dilakukan untuk dapat mendapatkan sebuah gambaran yang lebih komprehensif mengenai kejadian fraktur di RSUD Dr Soetomo, Surabaya.

Perlu dikaji juga pentingnya perbaikan standar dan digitalisasi sistem rekam medis di RSUD Dr Soetomo, karena selama penelitian ini ditemukan masalah, yaitu: kurang lengkapnya data rekam medis, tidak teraturnya urutan halaman rekam medis, sistem penyimpanan yang kurang sempurna, dan kualitas tulisan yang bervariasi sehingga berakibat sebagian 
konten sulit (atau tidak bisa) terbaca.

\section{DAFTAR PUSTAKA}

Badan Penelitian dan Pengembangan Kesehatan Kementerian Kesehatan RI, (2013). Riset Kesehatan Dasar. Jakarta: Departemen Kesehatan Indonesia, pp.104-106.

Blows, S., Ivers, R., Connor, J., Ameratunga, S., Woodward, M. dan Norton, R. (2005). Unlicensed Drivers and Car Crash Injury. Traffic Injury Prevention, 6(3), pp.230-234.

Bonafede, M., Espindle, D. dan Bower, A. (2013). The direct and indirect costs of long bone fractures in a working age US population. Journal of Medical Economics, [online] 16(1), pp.169178. Available at: http://dx.doi.org/10.3111/13696998.2 012.737391 [Accessed 18 Aug. 2014].

Budd, L. (2012). Pediatric Fractures. [online] Learnpediatrics. Available at: http://learnpediatrics.com/bodysystems/musculoskeletalsystem/pediatric-fractures/ [Accessed 10 Aug. 2014].

Cannada, L. (2011). Open Fractures. [online] Orthoinfo.aaos.org. Available at:

http://orthoinfo.aaos.org/topic.cfm?to pic $=A 00582$ [Accessed 10 Jan. 2016].

Gill, A. dan Kelly, N. (2015). Prevention of falls in children. [online]

UpToDate. Available at:

http://www.uptodate.com/contents/pr evention-of-falls-in-children

[Accessed 11 Jan. 2016].

Hackney, L. dan Dodds, S. (2011). Assessment of scaphoid fracture healing. Current Reviews in Musculoskeletal Medicine, 4(1), pp.16-22.

Hart, E., Luther, B. dan Grottkau, B. (2006). Broken Bones: Common Pediatric Lower Extremity Fractures Part III. Orthopaedic Nursing, 25(6), pp.390407.

Igho, O., Isaac, O. dan Eronimeh, O. (2015). Road Traffic Accidents and Bone Fractures in Ughelli, Nigeria. IOSR Journal of Dental and Medical Sciences, [online] 14(4), pp.21-25. Available at: http://www.iosrjournals.org/iosrjdms/papers/Vol14-issue4/Version5/D014452125.pdf [Accessed 9 Jan. 2016].

Korlantas Polri, (2013). Injury Type. [online] Available at: http://korlantasirsms.info/graph/ageInjuryData [Accessed 21 Jan. 2016].

Moran, C., Wenn, R., Sikand, M. dan Taylor, A. (2005). Early mortality after hip fracture: is delay before surgery important? The Journal of Bone $1 \&$ Joint Surgery, 87(3), pp.483--489.

Nantulya, V. (2002). The neglected epidemic: road traffic injuries in developing countries. BMJ, 324(7346), pp.1139-1141.

Pamungkas, F., Hariyanto, T. dan Woro U, E. (2015). Identifikasi Ketidaklengkapan Dokumen Rekam Medis Rawat Inap di RSUD Ngudi Waluyo Wlingi. Jurnal Kedokteran Brawijaya, 28(2), pp.124-128.

Peden, M. (2004). World report on road traffic injury prevention. Geneva: World Health Organization.

Riyadina, W, Permana, M, dan Suhardi. (2009). Pola dan Determinan Sosiodemografi Cedera Akibat Kecelakaan Lalu Lintas di Indonesia. Majalah Kedokteran Indonesia, 
59(10), pp.464-472.

Robert Wood Johnson University Hospital, (2012). Head Injury in Children. [online] Available at: http://www.rwjuh.edu/scc/healthlibr ary/39742.aspx [Accessed 18 Aug. 2014].

Rozari, A. dan Wibowo, Y. (2015). FaktorFaktor yang menyebabkan Kemacetan Lalu-Lintas di Jalan Utama kota Surabaya (Studi Kasus Di Jalan Ahmad Yani dan Raya Darmo Surabaya). Jurnal Penelitian Administrasi Publik, 1(1), pp.42-57.

Salter, R. (1999). Textbook of disorders and injuries of the musculoskeletal system. 1 st ed. Baltimore: Williams \& Wilkins.

Sharma, R., Ali, L. dan Ubbot, M. (2006). The Epidemiology of Fractures and Dislocations at District Hospital Kathua (J\&K). International Journal of Current Medical Science \& Practice, 14(2), pp.114-117.

Sleet, D., Ballesteros, M., Salazar, A., Pogostin, C., Huitric, M. dan Baldwin, G. (2012). Protect the Ones You Love: Child Injuries are Preventable. [online] CDC.gov. Available at: http://www.cdc.gov/safechild/NAP/b ackground.html [Accessed 11 Jan. 2016].

Staheli, L. (2008). Fundamentals of pediatric orthopedics. 1st ed. Philadelphia: Wolters Kluwer Health/Lippincott Williams \& Wilkins.

Tahir, A. (2005). Angkutan Massal Sebagai Alternatif Mengatasi Persoalan Kemacetan Lalu-lintas di Kota Surabaya. SMARTek, 3(3), pp.169182.

Valerio, G., Gallã̈*, F., Mancusi, C., Di Onofrio, V., Colapietro, M., Guida, P. dan Liguori, G. (2010). Pattern of fractures across pediatric age groups: analysis of individual and lifestyle factors. BMC Public Health, 10(1), p.656.

Vopat, M., Kane, P., Christino, M., Truntzer, J., McClure, P., Katarincic, J. dan Vopat, B. (2014). Treatment of diaphyseal forearm fractures in children. Orthop Rev (Pavia), 6(2).

Wicaksono, D., Fathurochman, R., Riyanto, B. dan Wicaksono, Y. (2014). Analisis Kecelakaan Lalu Lintas (Studi Kasus Jalan Raya Ungaran - Bawen). Jurnal Karya Teknik Sipil, 3(1), pp.203-213.

World Health Organization, (2012). Falls. [online] Available at: http://www.who.int/mediacentre/facts heets/fs344/en/ [Accessed 9 Feb. 2016]. 